\title{
In-vitro development of vitrified-warmed bovine oocytes after activation may be predicted based on mathematical modelling of cooling and warming rates during vitrification, storage and sample removal
}

\author{
Marina Sansinena a,b, *, \\ Maria Victoria Santos c,b , \\ Jorge Chirife a , \\ Noemi Zaritzky c,b a \\ a Facultad de Ingeniería y Ciencias Agrarias, Pontificia Universidad Católica Argentina, Av. Alicia Moreau de Justo \\ 1300, Caba, 1429, Argentina \\ b Consejo Nacional de Investigaciones Científicas y Técnicas, CONICET, Godoy Cruz 2290, Caba, 1425, Argentina \\ c Depto. de Ingeniería Química, Facultad de Ingeniería, Universidad Nacional de La Plata and Centro de Investigación \\ y Desarrollo en Criotecnología de Alimentos (CONICET-UNLP- CIC), Calle 47 y 116, La Plata, 1900, Argentina \\ Corresponding author: marina.sansinena@gmail.com (M Sansinena).
}

\begin{abstract}
Heat transfer during cooling and warming is difficult to measure in cryo-devices; mathematical modelling is an alternative method that can describe these processes. In this study, we tested the validity of one such model by assessing in-vitro development of vitrified and warmed bovine oocytes after parthenogenetic activation and culture. The viability of oocytes vitrified in four different cryodevices was assessed. Consistent with modelling predictions, oocytes vitrified using cryo-devices with the highest modelled cooling rates had significantly $(P<0.05)$ better cleavage and blastocyst formation rates. We then evaluated a two-step sample removal process, in which oocytes were held in nitrogen vapour for $15 \mathrm{~s}$ to simulate sample identification during clinical application, before being removed completely and warmed. Oocytes exposed to this procedure showed reduced developmental potential, according to the model, owing to thermodynamic instability and devitrification at relatively low temperatures. These findings suggest that cryodevice selection and handling, including method of removal from nitrogen storage, are critical to survival of vitrified oocytes. Limitations of the study include use of parthenogenetically activated rather than fertilized ova and lack of physical measurement of recrystallization. We suggest mathematical modelling could be used to predict the effect of critical steps in cryopreservation
\end{abstract}

Keywords: Embryo development Glass transition Heat transfer Oocyte Vitrification Warming

\section{Introduction}

Current advances in cryopreservation of human gametes have led to near-complete replacement of traditional slow cooling protocols by ultra-fast cooling methods (Boldt, 2011, Edgar and Gook, 2012; 
Kuleshova et al., 1999). Vitrification, described by Luyet (1937), refers to the solidification of a sample into an amorphous, glassy-state without intracellular and extracellular ice crystal formation. When applied to embryology, this process requires high concentrations of cryoprotectants, extremely rapid cooling rates and minimal handling volume (Jain and Paulson, 2006; Rall and Fahy, 1985). Description of thermodynamic events during cryopreservation is of great importance to elucidate what type of phenomenon is occurring: freezing, cooling, vitrification, thawing of ice in the sample or devitrification (Mazur, 1984). Devitrification events have been previously defined (Shaw and Jones, 2003; Yavin and Arav, 2007) as ice nuclei or crystals forming during warming of a vitrified solution. Therefore, measurement of temperature histories is necessary to establish whether vitrification or phase change transition (ice formation) takes place during cooling, and whether a vitrified sample undergoes devitrification during warming. Direct temperature measurement in cryodevices is often difficult (Choi and Bischof, 2010). Both the minimal volumes and the minute size of the cryo-devices for loading, plunging and storage of mammalian oocytes and embryos present a challenge. Although experimental observations through modified cryostereoscopes of sample crystallization during cooling and recrystallization fractures during warming have been reported (Yavin and Arav, 2007), direct observation and measurement of these events is not feasible for most laboratories. A useful alternative to predict time-temperature curves is the use of numerical modelling of the heat-transfer process. In the past decade, an increasing number of engineers have collaborated with researchers in the biomedical, embryology or life sciences fields to solve complex problems related to thermodynamic processes and, ultimately, to be able to predict heat and mass transfer processes and other kinetic-driven phenomena (Lunardini, 1981; Arce et al., 1983; Pham, 2008; Alexiades and Solomon, 1993; Diller, 1997; Baudot and Odagescu, 2004; Choi and Bischof, 2010). This numerical simulation approach is useful for predicting temperature histories and other important heat-transfer parameters, such as surface heat-transfer coefficients (Cleland et al., 1984; Sansinena et al., 2010, 2011, 2012; Santos et al., 2012), but it also contributes to the validation of experimental results and reduces the number and scope of experiments needed when assessing cryopreservation protocols (Choi and Bischof, 2010). Previously, our laboratory applied the finite element method, a numerical solution to heat conduction problems, for the prediction of heattransfer performance of cryo-devices used in oocyte and embryo vitrification (Sansinena et al., 2011). This mathematical approach was also used to describe thermodynamic conditions during storage and warming of vitrified oocytes and embryos in relation to their glass transition rubbery state and to predict sample devitrification thresholds (Sansinena et al., 2014). To validate these numerical models, however, it is important to relate numerical predictions with cell survival and embryo development. Therefore, the objective of this study was to find the relationship between previously reported numerical simulations with in-vitro performance during cooling and warming of samples in cryo-devices. The modelled cooling and warming conditions (Sansinena et al., 2011, 
2014) were replicated in vitro, followed by analysis of morphological oocyte survival and in-vitro embryo development after parthenogenetic activation in a bovine model.

\section{Materials and methods}

\section{Selection of experimental conditions based on previous numerical models}

The experimental conditions for oocyte vitrification, sample storage and warming were selected on the basis of conditions previously modelled in theoretical analyses (Sansinena et al., 2011, 2014) for several cryo-devices, including Cryoloop, Cryotop, Miniflex and Open PulledStraw (OPS).

\section{Experiment: in-vitro oocyte survival and embryo development after vitrification in cryo- devices previously simulated by numerical model}

Oocyte in-vitro maturation and vitrification. Bovine ovaries were recovered from selected abattoirs classified as 'Exportation Accredited' by Animal Health National Service (Servicio Nacional de Seguridad Animal, SENASA, Argentina), with all the regulatory, animal health and slaughter practice that such accreditation entails. Ovaries were collected and transported to the laboratory at $30^{\circ} \mathrm{C}$ in saline solution supplemented with antibiotics within $2 \mathrm{~h}$ of slaughter (Blondin and Sirard, 1995); cumulus-oocyte complexes were aspirated by follicular puncture. Classification of cumulusoocyte complex quality was conducted following International Embryo Technology Society guidelines (Grade 1 [excellent] to Grade 4 [poor]). Only those oocytes classified as grades 1 and 2 were selected for in-vitro maturation. Cumulus-oocyte complexes were matured in Earl'sbased Medium 199 (Invitrogen 11150-059, MA, USA) supplemented with 10\% v/v heat-inactivated fetal bovine serum (FBS) (Gibco 10082- 139, US-origin), 5 l/ml porcine FSH (Sigma F 2293, MO, USA), $10 \mathrm{~g} / \mathrm{ml}$ luteinizing hormone releasing hormone (Sigma $\mathrm{H}$ 8008), $1 \mathrm{~g} / \mathrm{ml} 17$ beta-oestradiol (Sigma E 2758, MO, USA) and $1 \mathrm{~g} / \mathrm{ml}$ cysteamine (Sigma M 9768, MO, USA) in 5\% CO2 in humidified air incubator at $38.5^{\circ} \mathrm{C}$ for $22 \mathrm{~h}$. After $22 \mathrm{~h}$ of in-vitro maturation, oocytes were partially denuded of cumulus by gentle pipetting in $0.1 \%$ v/v hyaluronidase (350 IU, Sigma H 3506, MO, USA) solution. Oocytes were then washed three times in holding medium consisting of Hank's-base Medium 199 (Invitrogen 12350-039, MA, USA), supplemented with 10\% v/v fetal bovine serum (FBS) and randomly allocated to Cryoloop, Cryotop, OPS or Miniflex cryo-devices. Stepwise vitrification protocol consisting of ethylene glycol (Sigma 03747, MO, USA), dimethylsulphoxide (Me2SO) (Sigma C 6164, MO, USA) and trehalose (Sigma T 0167, MO, USA) was adapted from Lane et al. (1999a; 1999b). Oocytes were exposed for $45 \mathrm{~s}$ to vitrification solution 1 consisting of $0.7 \mathrm{M} \mathrm{Me} 2 \mathrm{SO}$ 
plus $0.9 \mathrm{M}$ ethylene glycol prepared in Hank's-based Medium 199 (Invitrogen 12350-039), supplemented with $10 \% \mathrm{v} / \mathrm{v}$ FBS. Next, oocytes were moved for $45 \mathrm{~s}$ to vitrification solution 2 , containing 1.4 M Me2SO plus 1.8 M ethylene glycol. Finally, oocytes were immersed in vitrification solution 3, consisting of $2.8 \mathrm{M} \mathrm{Me} 2 \mathrm{SO}$ plus $3.6 \mathrm{M}$ ethylene glycol plus $0.65 \mathrm{M}$ trehalose for $20 \mathrm{~s}$, immediately loaded onto cryo-device and then directly plunged into liquid nitrogen. Loading procedure of cryo-device was conducted as previously described for Cryoloop (Lane et al., 1999a, 1999b), Cryotop (Kuwayama, 2007), Miniflex (Tominaga and Hamada, 2001) and OPS (Vajta et al., 1998).

Warming. In all cases, warming procedure consisted of immediate direct immersion of the cryodevice into step-wise dilutions of $0.25 \mathrm{M}, 0.19 \mathrm{M}$ and $0.125 \mathrm{M}$ trehalose in Hank's-based Medium 199 supplemented with $10 \% \mathrm{FBS}$ at $37^{\circ} \mathrm{C}$ (Lane et al., 1999b). Oocytes were then transferred to Earl's-based Medium 199 supplemented with 10\% v/v FBS and allowed to equilibrate in a 5\% CO2 incubator for $1 \mathrm{~h}$ before evaluation and subsequent parthenogenetic activation.

Assessment of oocyte survival, parthenogenetic activation and embryo culture. Oocytes were stored in liquid nitrogen for a minimum of $24 \mathrm{~h}$ and a maximum of 2 weeks before warming, survival assessment and parthenogenetic activation. Vitrified-warmed oocytes and non-vitrified, fresh control oocytes were stripped of remaining cumulus in $1 \mathrm{mg} / \mathrm{ml}$ hyaluronidase solution. Morphologically intact oocytes after warming were identified by presence of homogeneous ooplasm, continuous oolemic membrane and non-fractured zona pellucida, and were subjected to parthenogenetic activation protocol. Parthenogenesis was selected in lieu of IVF in this model to eliminate variability introduced by sperm co-incubation and failure of sperm penetration or fertilization caused by to zona hardening. Oocytes were parthenogenetically activated as previously described (Campbell et al., 1996). Briefly, chemical activation was conducted by 5 -min exposure to $5 \mathrm{M}$ ionomycin (Sigma, I 0634) at room temperature followed by a 3-h incubation in $2.5 \mathrm{mM} 6$ dimethylaminopurine prepared in SOFaaci culture medium (Holm et al., 1999). Oocytes were then cultured in 35-I droplets of SOFaaci medium (five presumptive activated oocytes/culture droplet) in a modular incubator chamber (Billups-Rothenberg, Del Mar, CA) at $38.5^{\circ} \mathrm{C}$ and $5 \% \mathrm{O} 2,5 \% \mathrm{CO} 2$ and $90 \% \mathrm{~N} 2$ in a humidified atmosphere. Activated oocytes were evaluated for cleavage after 2 days of invitro culture and the medium was then replaced with SOFaai with $5 \% \mathrm{v} / \mathrm{v} \mathrm{FBS}$, and culture was continued for 7 more days.

\section{Experiment 2: in-vitro oocyte survival and embryo development after different warming conditions previously simulated by numerical model}

Oocytes were vitrified in OPS cryo-device as previously described in the section 'Oocyte in-vitro maturation and vitrification', and exposed to storage conditions in either LN2 immersion or nitrogen vapour suspension (10 cm above LN2). Measured storage temperature range (Testo 735-1 digital 
thermometer and copper-nickel probe, NJ, USA) was $-165^{\circ} \mathrm{C}$ (corresponding to samples suspended in nitrogen vapour at $22 \mathrm{~cm}$ below neck of Dewar) to $-196^{\circ} \mathrm{C}$ (corresponding to samples immersed in liquid nitrogen) in liquid nitrogen; this range corresponds to the temperature stratification occurring in an undisturbed vapour phase, with sample canister suspended $22 \mathrm{~cm}$ from neck of MVE XC20 Dewar (vapour suspension condition) to temperature of LN2 $\left(-196^{\circ} \mathrm{C}\right)$ (liquid nitrogen immersion. Vitrified oocytes were stored under those conditions for a maximum of 1 month. Previously modelled (Sansinena et al., 2014) storage and sample removal conditions were replicated for the in- vitro study: one-step removal from LN2 immersion; one-step removal from N2-vapour phase suspension; and twostep removal from N2-vapour, with 15-s pause at neck of a 20-L Dewar (MVE XC20, Millenium 2000, Chart Biomedical, GA, USA), a condition simulating time required to read sample identification. The twostep protocol was applied only to vapour-suspended samples because it was hypothesized that these conditions were of highest thermodynamic instability. Two-step removal from LN2 immersion would have better simulated a clinical setting; however, it should be noted that no significant difference was found in samples stored immersed in LN2 or in the vapour phase. Sample removal conditions are presented in Figure 1. Warming, assessment of oocyte survival, parthenogenetic activation and embryo culture were conducted as previously described in the sections on 'Warming' and 'Assessment of oocyte survival, parthenogenetic activation and embryo culture'.

\section{Statistical analysis}

In all experiments, parthenogenetically activated non-vitrified metaphase-Il oocytes served as controls. Differences among treatment groups were compared using GraphPad Prism version 7.00 for Windows, GraphPad Software, La Jolla California, USA. Categorical outcomes were tabulated and set up as contingency $2 \times 2$ tables; overall data were analysed using chi-squared followed by Bonferroni post-hoc adjustment for multiple pairwise comparisons. The level of significance was set at $P<0.05$ /number of pairwise tests performed.

\section{Results}

\section{Experiment 1: in-vitro oocyte survival and embryo development after vitrification in cryo- devices previously simulated by numerical model}

A total of 943 metaphase-II bovine oocytes were used in four separate experiments. Results are presented in Table 1 ; cooling rates $\left({ }^{\circ} \mathrm{C} / \mathrm{min}\right.$, taken from Sansinena et al., 2011) were also included in this table for comparison. No significant difference was found in morphological oocyte survival between vitrified and non-vitrified groups. No significant differences were detected in the proportion 
of cleaved from oocytes vitrified in Cryoloop and Cryotop compared with non-vitrified control. Cleavage rate, however, was significantly higher for Cryotop and Cryoloop compared with Miniflex and OPS $(67 \%$ and $70 \%$ versus $40 \%$ and $43 \%$, respectively) $(P<0.05)$. In all cases, vitrified oocytes had significantly lower blastocyst formation and hatching rates than non-vitrified controls $(P<0.05)$. No significant difference was found in the proportion of oocytes reaching blastocyst stage when vitrified using Cryoloop or Cryotop cryodevices (17\% versus $19 \%$, respectively). Similarly, no significant

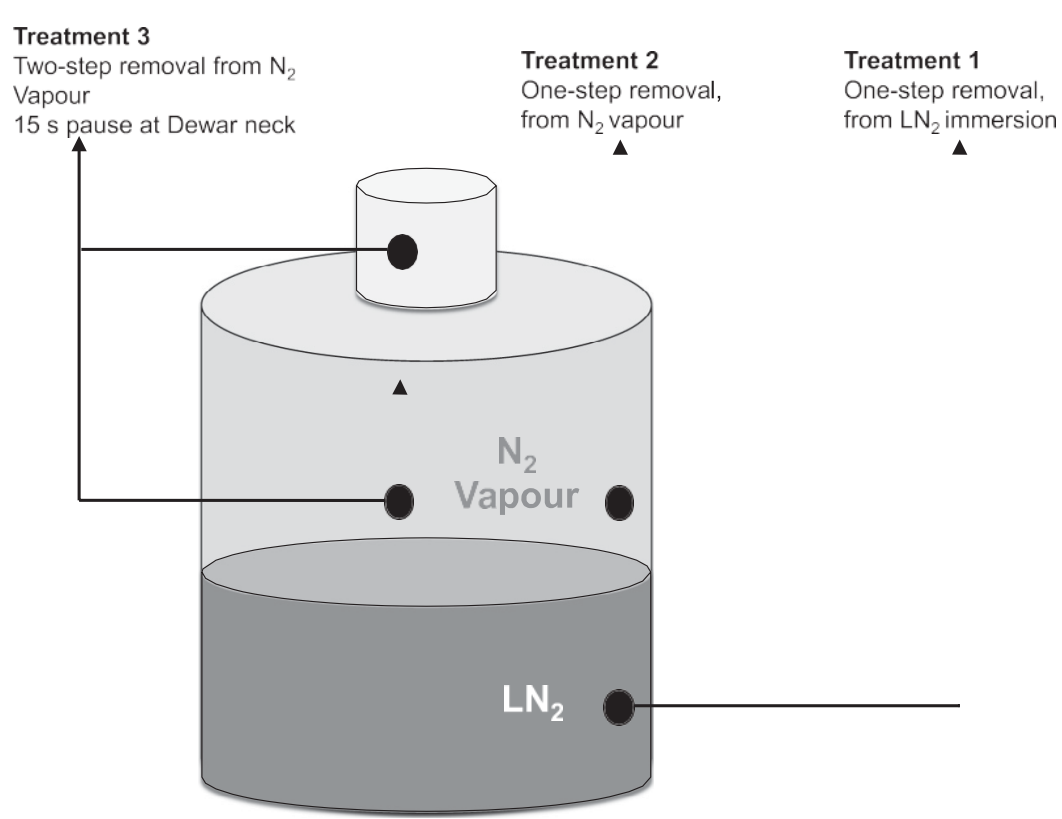

Figure 1 - Storage and sample removal conditions in Experiment 2.

difference was found in the proportion of oocytes reaching blastocyst stage when vitrified using Miniflex or OPS cryo-devices ( $8 \%$ versus $11 \%$, respectively). A significant difference $(P<0.05)$ was, however, found in the proportion of vitrified oocytes reaching blastocyst stage when vitrified with Cryoloop or Cryotop versus Miniflex or OPS (17\% and 19\% versus 8 and $11 \%$, respectively). The proportion of hatched embryos from oocytes vitrified in Cryotop, Cryoloop and OPS were not significantly different among treatments, but were all significantly lower $(P<0.05)$ than non-vitrified control. There were no hatched embryos produced from oocytes vitrified using Miniflex.

\section{In-vitro oocyte survival and embryo development after different warming conditions previously simulated by numerical model}

A total of 559 bovine oocytes vitrified in OPS cryo-device were used in three separate experiments. Results are presented in Table 2. All vitrified-warmed samples had significantly lower cleavage rate than non-vitrified controls $(P<0.05)$. A significant reduction in morphological oocyte survival was observed with two-step removal from Dewar when compared with either one-step removal treatment (samples completely immersed in LN2 or N2-vapour storage) and non-vitrified control (50\% versus $98.5 \%, 91 \%$ and $100 \%$, respectively; P< $0.05)$. Embryo cleavage rate was significantly reduced in the two-step removal treatment compared with both 
one-step removal treatments (LN2 immersed and N2 vapour storage) (52\% versus 70\% and 68\%, respectively; $\mathrm{P}<0.05)$. Blastocyst rates in all vitrified-warmed groups were significantly lower than nonvitrified control $(17 \%, 17 \%$ and $9 \%$ versus $33 \%$; $P<0.05)$. Blastocyst development was significantly reduced in two-step removal treatment versus both one-step removal treatments (LN2-immersed or N2-vapourstorage) (9\% versus $17 \%$ and $17 \%$; $P<0.05)$. No significant difference was found between proportions of embryos reaching blastocyst stage between onestep removal treatments.

\section{Discussion}

This study demonstrates experimentally that numerical modelling is a useful predictor of sample stability during vitrification, storage and warming. As predicted by the model, survival and development of vitrified parthenogenetically activated bovine oocytes was best in cryodevices with the highest modelled cooling rates. Furthermore,

\begin{tabular}{|c|c|c|c|c|c|}
\hline $\begin{array}{l}\text { Cryo-device Predicted cooling rate } \\
\left({ }^{\circ} \mathrm{C} / \mathrm{min}\right)^{\mathrm{b}}\end{array}$ & $\begin{array}{l}\mathrm{n} \text { vitrified/ } \\
\text { activated }\end{array}$ & $\begin{array}{l}\text { Morphologically } \\
\text { intact, } \mathrm{n}(\%)\end{array}$ & $\begin{array}{l}\text { Cleaved } \\
\text { (day 2), a n (\%) }\end{array}$ & $\begin{array}{l}\text { Blastocyst } \\
\text { (day 7), a n (\%) }\end{array}$ & $\begin{array}{l}\text { Hatched } \\
\text { (day9), an (\%) }\end{array}$ \\
\hline Cryoloop (180000) & 187 & $185(98.9)$ & $124(67.0)^{\mathrm{c}}$ & $31(16.8)^{c}$ & $4(2.2)^{c}$ \\
\hline Cryotop (60000) & 189 & $189(100)$ & $132(69.8)^{c}$ & $36(19.0)^{c}$ & $6(3.2)^{c}$ \\
\hline Miniflex (8738) & 186 & $158(84.9)$ & $63(39.9)^{d}$ & $13(8.2)^{d}$ & 0 \\
\hline OPS (7826) & 191 & $166(86.9)$ & $71(42.8)^{d}$ & $19(11.4)^{d}$ & $2(1.2)^{\mathrm{c}}$ \\
\hline Non-vitrified control $n / a$ & 190 & $190(100)$ & $165(86.8)^{c}$ & $69(36.3)^{\mathrm{e}}$ & $47(24.7)^{d}$ \\
\hline \multicolumn{6}{|c|}{$\begin{array}{l}\text { a Values based on morphologically intact oocytes. } \\
\text { b Adapted from Sansinena et al. (2011). The heat transfer coefficient, } \mathrm{h} \text {, is taken as } 2000 \mathrm{~W} / \mathrm{m}^{2} \mathrm{~K} \text {. } \\
\text { c-e Values with different superscripts within a column are statistically different, } \mathrm{P}<0.05 \text {. } \\
\text { OPS, Open Pulled-Straw. }\end{array}$} \\
\hline
\end{tabular}

\begin{tabular}{|c|c|c|c|c|c|c|c|}
\hline & $\begin{array}{l}\text { Temperature } \\
\left({ }^{\circ} \mathrm{C}\right) \\
\text { exposure }\end{array}$ & $\begin{array}{l}\text { Sample storage } \\
\text { temperature } \\
\text { T versus } \text { Tg }^{\text {a }}\end{array}$ & $\begin{array}{l}\mathrm{n} \text { vitrified/ } \\
\text { activated }\end{array}$ & $\begin{array}{l}\text { Intact, } \\
\mathrm{n}(\%)\end{array}$ & $\begin{array}{l}\text { Cleaved } \\
\text { (day 2), } \\
n(\%)\end{array}$ & $\begin{array}{l}\text { Blastocyst } \\
\text { (day 7), } \\
\mathrm{n}(\%)\end{array}$ & $\begin{array}{l}\text { Hatched } \\
\text { (day 9), } \\
\text { n (\%) }\end{array}$ \\
\hline $\begin{array}{l}\text { One-step removal- } \mathrm{LN}_{2} \\
\text { immersed storage }\end{array}$ & $-196\left(\mathrm{LN}_{2}\right)$ & $\begin{array}{l}\mathrm{T}<\mathrm{Tg} \\
\text { non-devitrification condition } \mathrm{T}\end{array}$ & 135 & $133(98.5)^{\dagger}$ & $93(69.9)^{f}$ & $23(17.3)^{f}$ & $4(3.0)^{f}$ \\
\hline $\begin{array}{l}\text { One-step removal-LN }{ }_{2} \\
\text { vapour storage }\end{array}$ & $\begin{array}{l}-165 \text { to }-196 \\
\left(\mathrm{LN}_{2} \text { vapor }\right)\end{array}$ & $\begin{array}{l}<\mathrm{Tg} \\
\text { non-devitrification condition } \mathrm{T}\end{array}$ & 140 & $127(90.7)^{f}$ & $86(67.7)^{\dagger}$ & $22(17.3)^{f}$ & $3(2.4)^{f}$ \\
\hline $\begin{array}{l}\text { Two-step removal } \mathrm{LN}_{2} \\
\text { vapour storage }^{e}\end{array}$ & $\begin{array}{l}-165 \text { to }-196 \\
\left(\mathrm{LN}_{2} \text { vapor) }\right. \\
-17^{\circ} \mathrm{C} \\
\text { (Dewar neck) NA }\end{array}$ & $\begin{array}{l}>\mathrm{Tg} \\
\text { devitrification condition }\end{array}$ & 135 & $67(49.6)^{g}$ & $35(52.2)^{9}$ & $6(9.0)^{9}$ & 0 \\
\hline Non-vitrified, control oocytes & & NA & 149 & $149(100)^{\dagger}$ & $123(82.6)^{\mathrm{h}}$ & $49(32.9)^{\mathrm{h}}$ & $29(19.5)^{9}$ \\
\hline \multicolumn{8}{|c|}{ 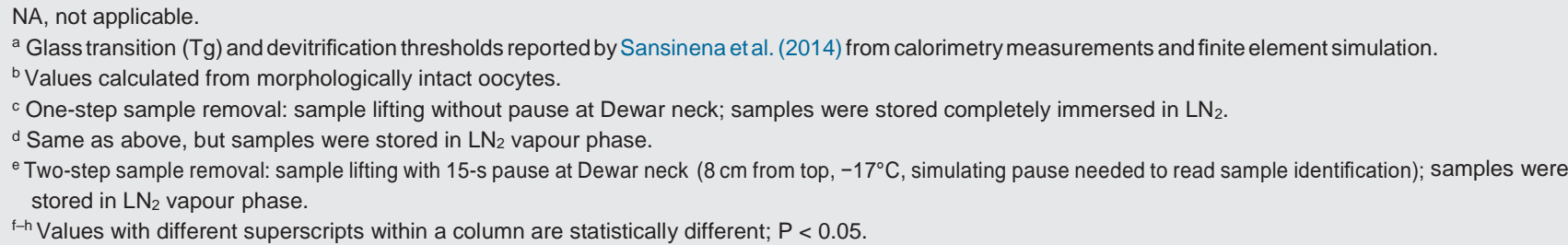 } \\
\hline
\end{tabular}

exposure to a short delay before complete removal from nitrogen vapour during warming (two-step removal) reduced development potential, according to the model, owing to thermodynamic instability and devitrification 
at relatively low temperatures. The experimental system in this study consisted of activated bovine oocytes. Bovine oocytes can be activated by exposure to ionomycin, ionophore, ethanol, or electric stimuli, among others (Graham, 1974). These chemical activation protocols have been shown to consistently support embryo development to blastocyst or hatched blastocyst stages in rates comparable to those of in vitro-derived counterparts (De La Fuente and King, 1998; Graham, 1974; Wang et al., 2008); the use of this model for evaluating vitrified oocyte competence and cryosurvival has been extensively documented in several species, including pigs (Somfai et al., 2006; Wu et al., 2017), cattle (Hou et al., 2009; Kubota et al., 1998), goat (Begin et al., 2003), sheep (Asgari et al., 2011), mice (Endoh et al., 2007; Huang et al., 2008; Yan et al., 2010) and humans (Imesch et al., 2013; Paffoni et al., 2007, 2008). The three reasons for considering chemical activation instead of conventional IVF as a model for this study were as follows: parthenogenesis by chemical activation has been used to study pre-implantation embryonic development in domestic species and humans and has been proposed to be a useful model for evaluating oocyte competence; parthenogenesis has been previously used to evaluate vitrified oocyte developmental competence; and parthenogenesis addresses concerns about introducing confounding variables related to sperm co-incubation and vitrificationrelated zona hardening. The reduced ability of spermatozoa to penetrate zona pellucida after vitrification has been reported in several species (Rusciano et al., 2017; Wiesak et al., 2017) and may, in part, explain why oocyte vitrification seems to have better results when it is followed by intracytoplasmic sperm injection instead of IVF (Kazem et al., 1995). Nonetheless, because in-vitro development of parthenotes may differ from that of zygotes, owing to differences in gene expression profiles (Gomez et al., 2009; Winger et al., 1997; Labrecque and Sirard, 2011), this may be considered a weakness of our study, and further research should include validation in murine IVF models. Results obtained in the present study are consistent with previous reports of decreased in-vitro developmental potential of embryos derived from vitrified oocytes. In the bovine species, several reports have indicated reduced cleavage and blastocyst development rates of vitrified oocytes following IVF or parthenogenetic chemical activation, when compared with non-vitrified controls (Dinnyés et al., 2000; Punyawai et al., 2015). This decreased developmental potential has been reported extensively for IVF or parthenogenetically derived embryos and not for vitrified oocytes used for intracytoplasmic sperm injection (Maavrides and Morroll, 2002) or nuclear transfer (Park et al., 2015). Previous reports have suggested spindle depolymerization caused by cryoprotectants (Caamaño et al., 2013; Martino et al., 1996; Parks and Ruffing, 1992; Vincent et al., 1987), compromised cytoskeletal microtubules, and chromosome mis-alignment (Caamaño et al., 2013; Coticchio et al., 2009) may explain why parthenogenetically activated 
and in vitro-fertilized vitrified oocytes seem to be more negatively affected than those used for nuclear transfer procedures. We previously reported the development of a mathematical model for predicting cooling rates achieved by several cryo-devices (Sansinena et al., 2011). The model showed that Cryoloop achieved the highest cooling rate, followed by Cryotop, Miniflex and OPS. In this study, invitro embryo cleavage and blastocyst development of oocytes vitrified in cryo-devices with higher heat transfer rates (Cryoloop and Cryotop) was significantly superior to that of cryo-devices with lower heat transfer performance (Miniflex and OPS). Although an identical comparison of the same four vitrification cryo-devices has not been conducted, results are consistent with those reported recently by Tsai et al. (2016), in which Cryotop was shown to have highest heat transfer rate and in-vitro performance compared with OPS and Fibreplugs. In addition, other investigators (Li et al., 2012, 2013; Liebermann and Tucker, 2002; Mandawala et al., 2016) have suggested that heat transfer during cooling is a crucially influential factor in the outcome of the vitrification procedure. Noteworthy, recent reports (Mazur and Paredes, 2016; Paredes and Mazur, 2016) have indicated that low cooling rates during vitrification might be ultimately associated with risks during warming resulting from potential sample devitrification and recrystallization; this recent evidence clearly indicates cooling and warming rates are thermodynamically linked and should be evaluated simultaneously in future studies.

Devitrification, defined as ice nuclei crystal formation during warming of a vitrified solution (Shaw and Jones, 2003), can result in irreversible damage during the warming of vitrified mammalian cells (Macfarlane, 1986; Macfarlane et al., 1981). In addition, recrystallization, described as growth of nucleated crystals in a formerly vitrified sample is also likely to occur during warming (Shaw and Jones, 2003). Although liquid nitrogen Dewars used for storing reproductive cells are filled to full capacity, evaporative loss may result in samples being partially suspended in nitrogen vapour, although this should not be a common occurrence. In addition, samples are also exposed to a vertical temperature gradient at the neck of the containers upon removal. Although this is generally not a matter of concern (as long as samples remains below glass transition for cytoplasm) in the cryostorage of frozen material such as semen straws and other cell suspensions (Gao and Critser, 2012), it becomes a risk when samples are cryopreserved in a more thermodynamically unstable condition such as vitrification. Several reports have indicated that, above the glass transition temperature of the cytoplasm, vitrified oocytes and embryos enter a liquid transition, promoting devitrification, followed by immediate ice nucleation and re-crystallization (Jin et al., 2010; Karlsson, 2001; Mazur, 1990). Our group (Sansinena et al., 2014) applied numerical modelling to predict events during sample handling and storage in liquid nitrogen Dewars. We determined the glass transition temperature for the vitrification solution using 
differential scanning calorimetry, and later solved heat conduction equations of the warming and devitrification thresholds during storage and upon sample removal of an OPS cryo-device, shown by modelling to demonstrate lower heat transfer efficiency (cryo-device least likely to be affected by sample removal conditions). The glass transition of samples stored in the vitrification solution ranged from -126 to $-121^{\circ} \mathrm{C}$, and the devitrification process under these conditions was initiated at $-109^{\circ} \mathrm{C}$. These findings also suggested the existence of a thermodynamically unstable rubbery state at $-121^{\circ} \mathrm{C}$, indicating that temperatures above this value could initiate devitrification, with adverse effects on cell survival. In the present study, the storage and sample removal under the conditions described were replicated experimentally. No significant differences were observed in the in-vitro development of chemically activated vitrified-warmed oocytes after one-step removal conditions, either with samples submerged in LN2 or stored in N2 vapour; these results are in agreement with recommendations previously proposed in numerical modelling studies that temperature of the sample must remain below the transition temperature of the cryoprotectant solution (Karlsson, 2001). By contrast, the two-step removal condition, which clearly surpasses the transition temperature of the vitrification solution, resulted in a significant reduction of morphologically intact vitrifiedwarmed oocytes, as well as reduced in-vitro embryo development after activation. Under this condition, samples were exposed to temperatures shown to be in the range of rubbery and devitrification thresholds, which in turn resulted in decreased in-vitro developmental competence. These results reinforce the importance of exercising extreme cautions while handling vitrified material during routine laboratory procedures such as identification confirmation and inventory keeping, owing to their inherent thermodynamic instability. Cryostorage recommendations have been generally based on cells cryopreserved under equilibrium freezing conditions, and they do not necessarily apply to vitrified material, which are at risk of irreversible devitrification and cryodamage under subzero temperatures. Our findings suggest that cryodevice selection, handling, identification and removal from storage are critical aspects of in-vitro outcome; results also indicate numerical modelling could be used as a tool to predict the effects of these potentially critical steps.

\section{Acknowledgement}

This study was funded in part by Facultad de Ingeniería y Ciencias Agrarias, Universidad Católica Argentina; Centro de Investigación y Desarrollo en Criotecnología de Alimentos (CIDCA-CONICET); Universidad 
Nacional de La Plata; CONICET; Agencia Nacional de Promoción Científica y Tecnológica, Argentina. Authors have expressed no conflict of interest or financial affiliation with any commercial cryopreservation cryo-devices compared in the study.

\section{References}

Alexiades, V., Solomon, A.D., 1993. Mathematical Modelling of Melting and Freezing Processes. Hemisphere Publishing Corp., Taylor and Francis Publishing Office, Washington DC, USA.

Arce, J.A., Potluri, P.L., Schneider, K.C., Sweat, V.E., Dutson, T.R., 1983.

Modelling Beef carcass cooling using finite element technique. Trans. ASAE 26, 950-954.

Asgari, V., Hosseini, S.M., Ostadhosseini, S., Hajian, M., Nasr-Esfahani, M.H., 2011. Time dependent effect of post warming interval on microtubule organization, meiotic status, and parthenogenetic activation of vitrified in vitro matured sheep oocytes. Theriogenology 75, 904-910.

Baudot, A., Odagescu, V., 2004. Thermal properties of ethylene glycol aqueous solutions. Cryobiology 48, 283-294.

Begin, I., Bhatia, B., Baldassarre, H., Dinnyes, A., Keefer, C.L., 2003. Cryopreservation of goat oocytes and in vivo derived 2-to 4-cell embryos using the cryoloop (CLV) and solid-surface vitrification (SSV) methods. Theriogenology 59, 1839-1850.

Blondin, P., Sirard, M.-A., 1995. Oocyte and follicular morphology as determining characteristics for developmental competence in bovine oocytes. Mol. Reprod. Dev. 41, 54-62.

Boldt, J., 2011. Current results with slow freezing and vitrification of the human oocyte. Reprod. Biom. Online 23, 314-322.

Caamaño, J.N., Díez, C., Trigal, B., Muñoz, M., Morató, R., Martín, D., Carrocera, S., Mogas, T., Gómez, E., 2013. Assessment of meiotic spindle configuration and post-warming bovine oocyte viability using polarized light microscopy. Reprod. Domest. Anim. 48, 470-476.

Campbell, K.H., Loi, P., Otaegui, P.J., Wilmut, I., 1996. Cell cycle co- ordination in embryo cloning by nuclear transfer. Reproduction 1, 40-46. 
Choi, J., Bischof, J.C., 2010. Review of biomaterial thermal property measurements in the cryogenic regime and their use for prediction of equilibrium and non-equilibrium freezing applications in cryobiology. Cryobiology 60, 52-70.

Cleland, D.J., Cleland, A.C., Earle, R.L., Byrne, S.J., 1984. Prediction of rates of freezing, thawing or cooling in solids of arbitrary shape using the finite element method. Int. J. Refrig. 7, 6-13.

Coticchio, G., Bromfield, J.J., Sciajno, R., Gambardella, A., Scaravelli, G., Borini, A., Albertini, D.F., 2009. Vitrification may increase the rate of chromosome misalignement in the metaphase II spindle of human mature oocytes. Reprod. Biomed. Online 19, 29-34.

De La Fuente, R., King, W.A., 1998. Developmental consequences of karyokinesis without cytokinesis during the first mitotic cell cycle of bovine parthenotes. Biol. Reprod. 58, 952-962.

Diller, K.R., 1997. Engineering-based contributions in cryobiology.

Cryobiology 34, 304-314.

Dinnyés, A., Dai, Y., Jiang, S., Yang, X., 2000. High developmental rates of vitrified bovine oocytes following parthenogenetic activation, in vitro fertilization, and somatic cell nuclear transfer. Biol. Reprod. 63, 513-518.

Edgar, D.H., Gook, D.A., 2012. A critical appraisal of cryopreservation (slow cooling versus vitrification) of human oocytes and embryos. Human Reprod. Update 18, 536.

Endoh, K., Mochida, K., Ogonuki, N., Ohkawa, M., Shinmen, A., Ito, M., Kashiwazaki, N., Ogura, A., 2007. The developmental ability of vitrified oocytes from different mouse strains assessed by parthenogenetic activation and intracytoplasmic sperm injection. J. Reprod. Dev. 53, 1199-1206.

Gao, D., Critser, J.K., 2012. Mechanisms of cryoinjury in living cells. In: Standards for Tissue Banking, 13th ed. American Association of Tissue Banking, pp. 187-196.

Gomez, E., Caamano, J.N., Bermejo-Alvarez, P., Carmen, D.Í.E.Z., Munoz, M., Martin, D., Carrocera, S., Gutierrez-Adan, A., 2009. Gene expression in early expanded parthenogenetic and in vitro fertilized bovine blastocysts. J. Reprod. Dev. 55, 607-614.

Graham, C.F., 1974. The production of parthenogenetic mammalian embryos and their use in biological research. Biol. Rev. 49, 399-422.

GraphPad Prism version 7.00 for Windows, GraphPad Software, La Jolla California USA, www.graphpad.com. 
Holm, P., Booth, P.J., Scmidt, M.H., Greve, T., Callesen, H., 1999. High bovine blastocyst development in a static in vitro production system using SOFaa medium supplemented with sodium citrate and myo-inositol with or without serum proteins. Theriogenology 52, 683-700.

Hou, Y.P., Liu, Y., Dai, Y.P., Li, R., Shi, W.Q., Wang, H.P., Wang, L.L., Li, N., Zhu, S.E., 2009. Improved parthenogenetic development of vitrified-warmed bovine oocytes activated with $9 \%$ ethanol plus 6-DMAP. Theriogenology 72, 643-649.

Huang, J.Y., Chen, H.Y., Park, J.Y.S., Tan, S.L., Chian, R.C., 2008.

Comparison of spindle and chromosome configuration in in vitro- and in vivo-matured mouse oocytes after vitrification. Fertil. Steril. 90, 1424-1432.

Imesch, P., Scheiner, D., Xie, M., Fink, D., Macas, E., Dubey, R., Imthurn, B., 2013. Developmental potential of human oocytes matured in vitro followed by vitrification and activation. J. Ovarian Res. 6, 30.

Stringfellow, D., Seidel, S., 1998. International Embryo Transfer Manual, 4th ed. IETS Publishing, Champaign, IL, USA, pp. 87-90.

Jain, J.K., Paulson, R.P., 2006. Oocyte cryopreservation. Fertil. Steril.

86, 1037-1046.

Jin, B., Mochida, K., Ogura, A., Hotta, E., Kobayashi, Y., 2010. Equilibrium vitrification of mouse embryos. Biol. Reprod. 82, 444-450.

Karlsson, J.O., 2001. A theoretical model of intracellular devitrification.

Cryobiology 42, 154-169.

Kazem, R., Thompson, L.A., Srikantharajah, A., Laing, M.A., Hamilton, M.P.R., 1995. Cryopreservation of human oocytes and fertilization by two techniques: in-vitro fertilization and intracytoplasmic sperm injection. Hum. Reprod. 10, 2650-2654.

Kubota, C., Yang, X., Dinnyes, A., Todoroki, J., Yamakuchi, H., Mizoshita, K., Inohae, S., Tabara, N., 1998. In vitro and in vivo survival of frozen- thawed bovine oocytes after IVF, nuclear transfer, and parthenogenetic activation. Mol. Reprod. Dev. 51, 281-286. 
Kuleshova, L., Gianaroli, L., Magli, C., Ferraretti, A., Trounson, A., 1999. Birth following vitrification of a small number of human oocytes: a case report. Human Reprod. 14, 3077-3079.

Kuwayama, M., 2007. Highly efficient vitrification for cryopreservation of human oocytes and embryos: the Cryotop method. Theriogenology 67, 73-80.

Labrecque, R., Sirard, M.A., 2011. Gene expression analysis of bovine blastocysts produced by parthenogenic activation or fertilisation. Reprod. Fertil. Dev. 23, 591-602.

Lane, M., Bavister, B., Lyons, E., Forest, K., 1999a. Container-less vitrification of mammalian oocytes and embryos. Nat. Biotech. 17, 1234-1236.

Lane, M., Schoolcraft, W.B., Gardner, D.K., 1999b. Vitrification of mouse and human blastocysts using a novel cryoloop container-less technique. Fertil. Steril. 72, 1073-1078.

Li, W., Zhou, X., Wang, H., Liu, B., 2012. Numerical analysis to determine the performance of different oocyte vitrification devices for cryopreservation. CryoLetters 33, 144-150.

Li, W., Zhou, X.L., Wang, H.S., Liu, B.L., Dai, J.J., 2013. Heat transfer coefficient of cryotop during freezing. CryoLetters 34, 255-260.

Liebermann, J., Tucker, M.K., 2002. Effect of carrier system on the yield of human oocytes and embryos as assessed by survival and developmental potential after vitrification. Reproduction 124, 483- 489 .

Lunardini, V.J., 1981. Heat Transfer in Cold Climates. Van Nostrand Reinhold Company, New York.

Luyet, B., 1937. The vitrification of organic colloids and of protoplasm.

Biodynamica 1, 1-14.

Maavrides, A., Morroll, D., 2002. Cryopreservation of bovine oocytes: is cryoloop vitrification the future to preserving the female gamete? Reprod. Nutr. Dev. 42, 73-80.

Macfarlane, D.R., 1986. Devitrification in glass-forming aqueous solutions. Cryobiology 23, 230-244.

Macfarlane, D.R., Angell, C.A., Fahy, G.M., 1981. Homogenous nucleation and glass formation in cryoprotective systems at high pressures. CryoLetters 2, 353-358.

Mandawala, A.A., Harvey, S.C., Roy, T.K., Fowler, K.E., 2016. 
Cryopreservation of animal oocytes and embryos: current progress and future prospects. Theriogenology $86,1637-1644$.

Martino, A., Pollard, J., Leibo, S.P., 1996. Effect of chilling bovine oocytes on their developmental competence. Mol. Reprod. Dev. 45, 503-512.

Mazur, P., 1984. Freezing of living cells: mechanisms and implications.

Am. J. Physiol. 247, 125-142.

Mazur, P., 1990. Equilibrium, quasi-equilibrium, and non-equilibrium freezing of mammalian embryos. Cell Biophys. 17, 53-92.

Mazur, P., Paredes, E., 2016. Roles of intracellular ice formation, vitrification of cell water, and recrystallisation of intracellular ice on the survival of mouse embryos and oocytes. Reprod. Fertil. Dev. 28, $1088-1091$.

Paffoni, A., Brevini, T.A., Somigliana, E., Restelli, L., Gandolfi, F., Ragni, G., 2007. In vitro development of human oocytes after parthenogenetic activation or intracytoplasmic sperm injection.

Fertil. Steril. 87, 77-82.

Paffoni, A., Brevini, T.A.L., Gandolfi, F., Ragni, G., 2008. Parthenogenetic activation: biology and applications in the ART laboratory. Placenta 29, 121-125.

Paredes, E., Mazur, P., 2016. Dehydration preparation of mouse sperm for vitrification and rapid laser warming. CryoLetters 37, 335-345.

Park, M.J., Lee, S.E., Kim, E.Y., Lee, J.B., Jeong, C.J., Park, S.P., 2015.

Effective oocyte vitrification and survival techniques for bovine somatic cell nuclear transfer. Cell Reprogram 17, 199-210.

Parks, J.E., Ruffing, N.A., 1992. Factors affecting low temperature survival of mammalian oocytes. Theriogenology 37, 59-73.

Pham, Q.T., 2008. Modelling of freezing processes. In: Evans, J.M. (Ed.), Frozen Food Science and Technology. pps. Blackwell Publishing, Oxford, pp. 51-80. 
Punyawai, K., Anakkul, N., Srirattana, K., Aikawa, Y., Sangsritavong, S., Nagai, T., Imai, K., Parnpai, R., 2015. Comparison of cryotop and micro volume air cooling methods for cryopreservation of bovine matured oocytes and blastocysts. J. Reprod. Dev. 61, 431-437.

Rall, W.F., Fahy, G.M., 1985. Ice-free cryopreservation of mouse embryos at $-196^{\circ} \mathrm{C}$ by vitrification. Nature 313, 573-575.

Rusciano, G., De Canditiis, C., Zito, G., Rubessa, M., Roca, M.S., Carotenuto, R., Sasso, A., Gasparrini, B., 2017. Raman-microscopy investigation of vitrification-induced structural damages in mature bovine oocytes. PLoS ONE 12, e0177677.

Sansinena, M., Santos, M.V., Zaritzky, N., Baeza, R., Chirife, J., 2010. Theoretical prediction of the effect of heat transfer parameters on cooling rates of liquid-filled plastic straws used for cryopreservation of spermatozoa. CryoLetters 31, 120-129.

Sansinena, M., Santos, M.V., Zaritzky, N., Chirife, J., 2011. Numerical simulation of cooling rates in vitrification systems used for oocyte cryopreservation. Cryobiology 63, 32-37.

Sansinena, M., Santos, M.V., Zaritzky, N., Chirife, J., 2012. Comparison of heat transfer in liquid and slush nitrogen by numerical simulation of cooling rates for French straws used for sperm cryopreservation. Theriogenology $77,1717-1721$.

Sansinena, M., Santos, M.V., Taminelli, G., Zaritzky, N., 2014.

Implications of storage and handling conditions on glass transition and potential devitrification of oocytes and embryos. Theriogenology 82, 373-378.

Santos, M.V., Sansinena, M., Zaritzky, N., Chirife, J., 2012. Assessment of the heat transfer coefficient during oocyte vitrification in liquid and slush nitrogen using numerical simulations to determine cooling rates. CryoLetters 33, 31-40.

Shaw, J.M., Jones, G.M., 2003. Terminology associated with vitrification and other cryopreservation procedures for oocytes and embryos. Hum. Reprod. Update 9,583-605.

Somfai, T., Dinnyés, A., Sage, D., Marosán, M., Carnwath, J.W., Ozawa, M., Kikuchi, K., Niemann, H., 2006. Development to the blastocyst stage of parthenogenetically activated in vitro matured porcine oocytes after solid surface vitrification (SSV). Theriogenology 66, 415-422. 
Tominaga, K., Hamada, Y., 2001. Gel loading tip as container for vitrification of in vitro produced bovine embryos. J. Reprod. Dev. 47, 267-273.

Tsai, S., Yang, V., Lin, C., 2016. Comparison of the cryo-tolerance of vitrified gorgonian oocytes. Sci. Rep. 6.

Vajta, G., Holm, P., Kuwayama, M., Booth, P.J., Jacobsen, H., Greve, T., Callesen, H., 1998. Open pulled straw (OPS) vitrification: a new way to reduce cryoinjuries of bovine ova and embryos. Mol. Reprod. Dev. 51, 5358.

Vincent, J.-P., Scharf, S.R., Gerhart, J.C., 1987. Subcortical rotation in Xenopus eggs: a preliminary study of its mechanochemical basis. Cell Motil. Cytoskel. 8,143-154.

Wang, Z.G., Wang, W., Yu, S.D., Xu, Z.R., 2008. Effects of different activation protocols on preimplantation development, apoptosis and ploidy of bovine parthenogenetic embryos. Anim. Reprod. Sci. 105, 292-301.

Wiesak, T., Wasielak, M., Złotkowska, A., Milewski, R., 2017. Effect of vitrification on the zona pellucida hardening and follistatin and cathepsin B genes expression and developmental competence of in vitro matured bovine oocytes. Cryobiology $76,18-23$. in press.

Winger, Q.A., De La Fuente, R., King, W.A., Armstrong, D.T., Watson, A.J., 1997. Bovine parthenogenesis is characterized by abnormal chromosomal complements: implications for maternal and paternal co-dependence during early bovine development. Dev. Genet. 21, 160.

Wu, G., Jia, B., Quan, G., Xiang, D., Zhang, B., Shao, Q., Hong, Q., 2017.

Vitrification of porcine immature oocytes: association of equilibration manners with warming procedures, and permeating cryoprotectants effects under two temperatures. Cryobiology 75, 21-27.

Yan, C.L., Fu, X.W., Zhou, G.B., Zhao, X.M., Suo, L., Zhu, S.E., 2010.

Mitochondrial behaviors in the vitrified mouse oocyte and its parthenogenetic embryo: effect of Taxol pretreatment and relationship to competence. Fertil. Steril. 93, 959-966.

Yavin, S., Arav, A., 2007. Measurement of essential physical properties of vitrification solutions. Theriogenology 67, 81-89. 